\title{
The emerging role of exosomes in epithelial-mesenchymal-transition in cancer
}

\author{
Laura Jayne Vella ${ }^{1,2}$ * \\ ' Ludwig Institute for Cancer Research, Melbourne-Austin Branch, Cancer Immunobiology Laboratory, Olivia Newton-John Cancer and Wellness Centre, Heidelberg, \\ VIC, Australia \\ ${ }^{2}$ The Florey Institute for Neuroscience and Mental Health, Parkville, VIC, Australia
}

\section{Edited by:}

Petranel Theresa Ferrao, Peter

MacCallum Cancer Centre, Australia

\section{Reviewed by:}

Frederique Gaits-lacovoni، INSERM

U1048, France

Clement M. Lee, Mount Sinai School

of Medicine, USA

\section{*Correspondence}

Laura Jayne Vella, The Florey Institute for Neuroscience and Mental Health 30 Royal Parade, Parkville, VIC 3052, Australia

e-mail: ljvella@unimelb.edu.au
Metastasis in cancer consists of multiple steps, including epithelial-mesenchymaltransition (EMT), which is characterized by the loss of epithelial-like characteristics and the gain of mesenchymal-like attributes including cell migration and invasion. It is clear that the tumor microenvironment can promote the metastatic cascade and that intercellular communication is necessary for this to occur. Exosomes are small membranous vesicles secreted by most cell types into the extracellular environment and they are important communicators in the tumor microenvironment. They promote angiogenesis, invasion, and proliferation in recipient cells to support tumor growth and a prometastatic phenotype. Although it is clear that exosomes contribute to cancer cell plasticity, experimental evidence to define exosome induced plasticity as EMT is only just coming to light. This review will discuss recent research on exosomal regulation of the EMT process in the tumor microenvironment.

Keywords: exosomes, cancer, extracellular vesicles, intercellular signaling

\section{INTRODUCTION}

Epithelial-mesenchymal-transition (EMT) is a process whereby epithelial cells undergo a shift in plasticity and acquire the ability to disseminate, invade, and cause metastasis. Established as a central process during the early stages of development, it is now clear that EMT has implications on cancer progression by triggering the loss of cell-cell adhesion to facilitate tumor cell invasion and remodeling of the extracellular matrix. While epithelial cells express high levels of E-cadherin and are closely connected to each other by tight junctions, mesenchymal cells express $\mathrm{N}$-cadherin, fibronectin, and vimentin, have a spindle-shaped morphology and less tight junctions.

Intercellular crosstalk between neighboring and distant tumor cells and immune and stromal cells in the tumor microenvironment plays a large role in cancer development, the establishment of the mesenchymal state, and metastasis. Intercellular crosstalk can occur by direct cell to cell contact or via factors secreted into the extracellular environment. Extracellular vesicles, called exosomes, have become recognized as important in cellular communication (1). Unlike soluble factors secreted by cells, exosomes carry a concentrated group of functional molecules, provide protection to the transported molecules and serve as intercellular communicators not only locally but also systemically.

Exosomes are formed from inward budding of the limiting membrane of multi-vesicular bodies (MVB) and are released from the cell into the extracellular environment upon fusion of the MVB with the plasma membrane. Most prokaryotic and eukaryotic cells release exosomes, including cancer cells such as colorectal (2), lung, breast, glioblastoma (GBM), ovarian, and melanoma (3). Exosomes from different cellular types contain a common set of molecules, as well as cell type-specific components. For example, exosomes derived from cancer cells contain proteins that reflect the endosomal origin of exosomes as well as cellular oncogenic drivers including receptor tyrosine kinases (RTKs), oncoproteins, phosphorylated proteins, and miRNA (2, 4-6). After release into the extracellular environment, exosomes act as discrete vesicles trafficking to distant and proximal recipient cells where they alter cell signaling and phenotype by transfer of bioactive molecules. Exosomes transfer their messages in different ways. Firstly, they can activate target cells through the transfer of ligands such as fibroblast growth factor (FGF), hepatocyte growth factor (HGF), vascular endothelial growth factor (VEGF) $(7,8)$, and epidermal growth factor (EGF) (9). Secondly, they can transfer receptors such as mutant EGFR (10) and HGFR (11) from one cell to another by fusion with the plasma membrane of recipient cells (10). This results in transfer of oncogenic activity via activation of growth factor signaling pathways in recipient cells $(11,12)$. The third mechanism of action involves endocytosis of the exosome and subsequent transfer of molecules directly into the cytosol of the recipient cell. These can include phosphorylated P13K, AKT, mTOR, cyclins, and cyclin-dependent kinases $(13,14)$ and miRNA, which can functionally repress target genes in the recipient cell (15).

Over the last decade, a number of studies have demonstrated that exosomes are mediators of the metastatic process. Exosomes derived from both normal and cancer cells can promote angiogenesis (16-19), invasion (20-23), and proliferation (24-26) in recipient cells to support tumor growth.

\section{CHANGES IN EXOSOME COMPOSITION ACCOMPANY THE TRANSITION TO A MESENCHYMAL STATE}

Epithelial-mesenchymal-transition entails morphological and phenotypic changes to a cell. To assess the composition of exosomes released from cells following these changes, several 
groups have induced EMT via transformation with oncogenic proteins such as Ras or EGFR (27-29). Exosomes released from Madin-Darby canine kidney (MDCK) cells transformed with oncogenic $\mathrm{H}$-Ras contained the EMT marker vimentin, in addition to matrix metalloproteases (MMPs), integrins, and key and core splicing complex components (29). Epithelial markers including E-cadherin and EpCAM were downregulated relative to exosomes from untransformed cells. It was postulated that exosomes from the transformed cells were capable of inducing EMT in recipient cells although no functional experiments were performed to validate this. Proteomic studies on EGFR (coupled with blockade of E-cadherin) induced EMT in A431 and DLD-1 epithelial cancer cells, revealed coordinated loss of EGFR and tissue factor (TF) from the cells (27). This coincided with an increase in exosome release, selective upregulation of TF in exosomes, and expression of 30 additional proteins unique to the mesenchymal cell-derived exosomes (28). The mesenchymal-like cells transferred TF to recipient endothelial cells via exosomes rendering the recipient cells procoagulant, suggesting EMT promotes exosome release and shedding of TF from cells via exosomes (27).

Jeppesen et al. studied the protein content of exosomes derived from a human bladder carcinoma cell line without metastatic capacity relatively to two isogenic derivate metastatic cell lines formed in the lung and liver of mice. Although proteins associated with EMT were found in exosomes derived from the metastatic cells (30), no functional studies correlating changes in protein content with alterations in exosome function were carried out, so it is unclear in this case if exosomes from the metastatic cell line had an increased metastatic potential. With that said, exosomes from a range of mesenchymal-like breast and ovarian cancer cell lines differentially impacted on recipient cells compared to epithelial-like cell lines (31). Exosomes from the mesenchymallike cell lines contained increased angiogenic molecules including PDGF, IL-8, and angiogenin suggested to promote AKT phosphorylation and subsequent activation of recipient endothelial cells (31).

\section{EMT INDUCERS ARE ASSOCIATED WITH EXOSOMES}

The protein composition of exosomes has been analyzed extensively, predominantly by mass spectrometry to reveal a defined subset of cellular proteins common to exosomes originating from a variety sources and species (32-35). Inducers of EMT have been found in association with exosomes including TGF $\beta$ (36), $\mathrm{TNF} \alpha$, IL-6, TSG101, AKT, ILK1, $\beta$-catenin $(37,38)$, hepatoma-derived growth factor, casein kinase II (CK2), annexin A2 (30), integrin 3 (39), caveolin-1 (40), and matrix metalloproteinases (41-44). Functional studies to demonstrate that exosome associated EMT inducers promote a prometastatic phenotype are outlined below.

The WNT signaling pathway participates in EMT by inhibiting glycogen synthase kinase- $3 \beta$ (GSK $3 \beta$ ) to stabilize $\beta$-catenin, promoting a gene expression program that favors EMT (45). Exosomes released from human and Drosophila cells contain WNT $(46,47)$, which can be transferred and activate WNT signaling in recipient cells (48-50). Luga et al. observed that WNT containing exosomes derived from cancer associated fibroblasts (CAFS) promoted motility and metastasis by activating autocrine WNT-planar cell polarity signaling in recipient breast cancer cells
(48). Similarly, mesenchymal stem cell (MSC) and macrophagederived exosomes (51) promoted migration and/or invasion of breast cancer via activation of WNT signaling (49). In melanoma, recombinant WNT5A induces the release of soluble mediators including IL-6, IL-8, VEGF, and MMP2 in association with exosomes (52) suggesting that not only does exosomal WNT promote EMT in recipient cells but it changes the composition of the released exosome to promote further EMT. Kock et al. examined the contribution of exosomes to cancer population equilibrium and tumor heterogeneity (53). They showed that diffuse large Bcell lymphomas possess a self-organized infrastructure comprising two populations of cells, where transitions between clonogenic states could be modulated by exosome-mediated WNT signaling (53). This study goes some way in broadening our understanding of the complex processes that maintain tumor cell heterogeneity and highlights exosomes as key players in this process.

Hypoxia in the tumor environment can promote EMT and several studies have provided evidence that hypoxia promotes the release of exosomes from different tumor cell types including breast, glioma, leukemia, and prostate $(38,54-57)$. Exosomes released by prostate cancer cells under hypoxic conditions contain more TGF $\beta$ IL-6, TNF $\alpha$, and MMP, TSG101, AKT, ILK1, and $\beta$-catenin (38), suggesting that they could differentially modulate recipient cells compared to exosomes from normal cells. Indeed, exosomes released from A431 carcinoma (58), glioma cells (55), and leukemia cells (54) promoted angiogenesis in recipient cells $(16,55)$. Similarly, exosomes derived from hypoxic GBM cells promoted tumor cell survival by inducing angiogenesis both in vitro and ex vivo through phenotypic modulation of endothelial cells and increased autocrine, promigratory activation of GBM cells (57).

Latent membrane protein 1 (LMP) of Epstein-Barr virus (EBV) contributes to the metastatic phenotype of nasopharyngeal carcinoma (NPC) by inducing EMT. Aga et al. (22) investigated if LMP1-positive exosomes could mediate EMT. They demonstrated that LMP1 positive exosomes and exosomal HIF1 $\alpha$ modulate expression of EMT markers in recipient cells (22). Following treatment with LMP1-positive exosomes, recipient cells expressed less E-cadherin and more $\mathrm{N}$-cadherin along with morphological spindle-like changes in cell shape indicative of EMT (22). Although exosome concentration was not reported and downstream signaling pathways associated with EMT were not examined, it is clear that LMP1-positive exosomal transmission of HIF $1 \alpha$ correlates with EMT-associated changes in the cadherin expression profile in recipient cells.

A growing number of miRNAs have been implicated in the regulation of EMT-related pathways in cancer (59) and in recent years exosomes have been reported to contain nucleic acid such as DNA, RNA, non-coding RNA, and miRNA (60-62). MiR-223, a miRNA specific for IL-4-activated macrophages, could be transported from macrophages to breast cancer cells via exosomes (63) to promote breast cancer cell invasion via modulation of the $\beta$-catenin pathway. Similarly, exosomes released from bone marrow-derived mesenchymal cells promoted multiple myeloma (MM) formation in an animal model by transfer of exosomal miR15a (64). Josson et al. recently performed one of the first studies to show that transfer of stromal-derived exosomal miRNA results 
in morphologically and biochemically defined EMT in cancer cells (65). Exosomes were isolated from normal prostate stromal cells overexpressing miR-409. Exosome associated miR-409-3p and -5p decreased the expression of target genes in prostate cancer cells and increased proliferation. Interestingly, 6 weeks after maintaining the prostate cancer cells in stromal cell media, the prostate cancer cells underwent EMT, which was biochemically defined by decreased E-cadherin and increased vimentin mRNA expression. In vivo, co-injection of prostate cancer cells and miR-409-overexpressing stromal fibroblasts resulted in tumor cells expressing miR-409 and enhance tumor growth suggesting that miR-409 was secreted out of stromal fibroblasts and taken up by the adjacent tumor. Further in vivo modeling however is required to conclude that stromalderived exosomes were responsible for transfer of miR-409 to surrounding cancer epithelial cells and subsequent tumor growth.

\section{EXOSOMES RELEASED FROM TUMOR CELLS PROMOTE PHENOTYPE CHANGE IN STROMAL CELLS}

The tumor microenvironment consists of a complex network consisting of an extracellular matrix populated by CAFs, endothelial cells, and immune cells. Exosomes derived from tumor cells communicate with stromal cells and vice-versa to promote tumor growth. MSCs have multi-lineage potential and can differentiate into a variety of cell types including tumor stromal cells, which are pro-tumorigenic. One way they do this is by promoting differentiation of MSCs, in some cases via mesenchymal-to-epithelial transition (MET).

Ovarian cancer cell-derived exosomes can induce adipose tissue-derived MSCs (ADSC) to exhibit the characteristics of CAFs, by increasing expression of TGF $\beta$ and activation of Smaddependent and -independent pathways (9). Similarly, gastric cancer exosomes trigger differentiation of umbilical cord-derived MSCs to CAFs through the TGF $\beta /$ Smad pathway (66) and breast and prostate cancer-derived exosomes can induce a myofibroblastic phenotype $(67,68)$. Together, these studies show that via activation of both Smad-dependent and -independent pathways, tumorderived exosomes can hijack MSCs to promote a prometastatic environment. In some cases, this process appears dependent on TGF $\beta 1$ expressed at the exosome surface in association with the transmembrane proteoglycan betaglycan (67). Although existing in a latent state, this complex was fully functional in eliciting Smaddependent signaling in recipient cells. Interestingly, myofibroblasts generated using soluble TGF $\beta 1$ were not pro-angiogenic or tumorpromoting, suggesting that exosomal TGF $\beta 1$ is required for the formation of tumor-promoting stroma (36).

In an elegant series of experiments, Abd Elmageed et al. demonstrated that tumor-tropic patient-derived ADSCs primed with prostate cancer cell-derived exosomes undergo genetic instability, MET, oncogenic transformation, and develop prostate tumors in vivo (69). Oncogenic transformation was associated with down-regulation of tumor suppressors upon delivery of prostate cancer-derived exosomal oncogenic $\mathrm{H}$-ras and $\mathrm{N}$-ras transcripts, Rab proteins, and oncogenic miRNA.

\section{CONCLUSION}

Exosomes play an important role in the development and progression of cancer. The studies outlined above highlight their role in the regulation of EMT-related pathways and suggest that tumor and stromal cells can regulate the invasiveness of cancer cells through exosome-mediated delivery of protein and miRNA. In the last decade, there has been an exponential increase in the number of studies aiming to understand the biology and composition of exosomes. These studies established that exosome composition changes upon transition to a mesenchymal state and that EMT inducers are associated with exosomes. In the last 2 years, experimental evidence has come to light defining exosome induced plasticity in recipient cells as EMT. Future investigations should further reveal how multiple cellular populations communicate via exosomes to promote a premetastatic phenotype and how exosomes can be employed for diagnostic and prognostic purposes to improve patient outcome.

\section{REFERENCES}

1. Roma-Rodrigues C, Fernandes AR, Baptista PV. Exosome in tumour microenvironment: overview of the crosstalk between normal and cancer cells. Biomed Res Int (2014) 2014:179486. doi:10.1155/2014/179486

2. Ji H, Greening DW, Barnes TW, Lim JW, Tauro BJ, Rai A, et al. Proteome profiling of exosomes derived from human primary and metastatic colorectal cancer cells reveal differential expression of key metastatic factors and signal transduction components. Proteomics (2013) 13(10-11):1672-86. doi:10.1002/pmic. 201200562

3. Zhang HG, Grizzle WE. Exosomes: a novel pathway of local and distant intercellular communication that facilitates the growth and metastasis of neoplastic lesions. Am J Pathol (2014) 184(1):28-41. doi:10.1016/j.ajpath.2013.09.027

4. Bellingham SA, Coleman BM, Hill AF. Small RNA deep sequencing reveals a distinct miRNA signature released in exosomes from prion-infected neuronal cells. Nucleic Acids Res (2012) 40(21):10937-49. doi:10.1093/nar/gks832

5. Cheng L, Quek CY, Sun X, Bellingham SA, Hill AF. The detection of microRNA associated with Alzheimer's disease in biological fluids using next-generation sequencing technologies. Front Genet (2013) 4:150. doi:10.3389/fgene.2013. 00150

6. Hill AF, Pegtel DM, Lambertz U, Leonardi T, O’Driscoll L, Pluchino S, et al. ISEV position paper: extracellular vesicle RNA analysis and bioinformatics. J Extracell Vesicles (2013) 2:22859. doi:10.3402/jev.v2i0.22859

7. Skog J, Wurdinger T, van Rijn S, Meijer DH, Gainche L, Sena-Esteves M, et al. Glioblastoma microvesicles transport RNA and proteins that promote tumour growth and provide diagnostic biomarkers. Nat Cell Biol (2008) 10(12):1470-6. doi: $10.1038 /$ ncb 1800

8. Thompson CA, Purushothaman A, Ramani VC, Vlodavsky I, Sanderson RD. Heparanase regulates secretion, composition and function of tumor cell-derived exosomes. J Biol Chem (2013) 288(14):10093-9. doi:10.1074/jbc.C112.444562

9. Cho JA, Park H, Lim EH, Kim KH, Choi JS, Lee JH, et al. Exosomes from ovarian cancer cells induce adipose tissue-derived mesenchymal stem cells to acquire the physical and functional characteristics of tumor-supporting myofibroblasts. Gynecol Oncol (2011) 123(2):379-86. doi:10.1016/j.ygyno.2011.08.005

10. Al-Nedawi K, Meehan B, Kerbel RS, Allison AC, Rak J. Endothelial expression of autocrine VEGF upon the uptake of tumor-derived microvesicles containing oncogenic EGFR. Proc Natl Acad Sci U S A (2009) 106(10):3794-9. doi:10.1073/pnas.0804543106

11. Peinado H, Aleckovic M, Lavotshkin S, Matei I, Costa-Silva B, Moreno-Bueno $\mathrm{G}$, et al. Melanoma exosomes educate bone marrow progenitor cells toward a pro-metastatic phenotype through MET. Nat Med (2012) 18(6):883-91. doi:10.1038/nm.2753

12. Al-Nedawi K, Meehan B, Micallef J, Lhotak V, May L, Guha A, et al. Intercellular transfer of the oncogenic receptor EGFRvIII by microvesicles derived from tumour cells. Nat Cell Biol (2008) 10(5):619-24. doi:10.1038/ncb1725

13. Gonzales PA, Pisitkun T, Hoffert JD, Tchapyjnikov D, Star RA, Kleta R, et al. Large-scale proteomics and phosphoproteomics of urinary exosomes. J Am Soc Nephrol (2009) 20(2):363-79. doi:10.1681/ASN.2008040406

14. Demory Beckler M, Higginbotham JN, Franklin JL, Ham AJ, Halvey PJ, Imasuen IE, et al. Proteomic analysis of exosomes from mutant KRAS colon cancer cells identifies intercellular transfer of mutant KRAS. Mol Cell Proteomics (2013) 12(2):343-55. doi:10.1074/mcp.M112.022806 
15. Montecalvo A, Larregina AT, Shufesky WJ, Stolz DB, Sullivan ML, Karlsson JM, et al. Mechanism of transfer of functional microRNAs between mouse dendritic cells via exosomes. Blood (2012) 119(3):756-66. doi:10.1182/blood-2011-02338004

16. Millimaggi D, Mari M, D’Ascenzo S, Carosa E, Jannini EA, Zucker S, et al. Tumor vesicle-associated CD147 modulates the angiogenic capability of endothelial cells. Neoplasia (2007) 9(4):349-57. doi:10.1593/neo.07133

17. Grange C, Tapparo M, Collino F, Vitillo L, Damasco C, Deregibus MC, et al. Microvesicles released from human renal cancer stem cells stimulate angiogenesis and formation of lung premetastatic niche. Cancer Res (2011) 71(15):5346-56. doi:10.1158/0008-5472.CAN-11-0241

18. Taverna S, Flugy A, Saieva L, Kohn EC, Santoro A, Meraviglia S, et al. Role of exosomes released by chronic myelogenous leukemia cells in angiogenesis. Int J Cancer (2012) 130(9):2033-43. doi:10.1002/ijc.26217

19. Liu Y, Zhu XJ, Zeng C, Wu PH, Wang HX, Chen ZC, et al. Microvesicles secreted from human multiple myeloma cells promote angiogenesis. Acta Pharmacol Sin (2014) 35(2):230-8. doi:10.1038/aps.2013.141

20. Rappa G, Mercapide J, Anzanello F, Pope RM, Lorico A. Biochemical and biological characterization of exosomes containing prominin-1/CD133. Mol Cancer (2013) 12:62. doi:10.1186/1476-4598-12-62

21. Zhang W, Zhao P, Xu XL, Cai L, Song ZS, Cao DY, et al. Annexin A2 promotes the migration and invasion of human hepatocellular carcinoma cells in vitro by regulating the shedding of CD147-harboring microvesicles from tumor cells. PLoS One (2013) 8(8):e67268. doi:10.1371/journal.pone.0067268

22. Aga M, Bentz GL, Raffa S, Torrisi MR, Kondo S, Wakisaka N, et al. Exosomal HIF1alpha supports invasive potential of nasopharyngeal carcinoma-associated LMP1-positive exosomes. Oncogene (2014) 33(37):4613-22. doi:10.1038/onc. 2014.66

23. Kobayashi M, Salomon C, Tapia J, Illanes SE, Mitchell MD, Rice GE. Ovarian cancer cell invasiveness is associated with discordant exosomal sequestration of Let7 miRNA and miR-200. J Transl Med (2014) 12:4. doi:10.1186/1479-5876-12-4

24. Arscott WT, Tandle AT, Zhao S, Shabason JE I, Gordon K, Schlaff CD, et al. Ionizing radiation and glioblastoma exosomes: implications in tumor biology and cell migration. Transl Oncol (2013) 6(6):638-48. doi:10.1593/tlo.13640

25. Soldevilla B, Rodriguez M, San Millan C, Garcia V, Fernandez-Perianez R, GilCalderon B, et al. Tumor-derived exosomes are enriched in DeltaNp73, which promotes oncogenic potential in acceptor cells and correlates with patient survival. Hum Mol Genet (2014) 23(2):467-78. doi:10.1093/hmg/ddt437

26. Wang J, Hendrix A, Hernot S, Lemaire M, De Bruyne E, Van Valckenborgh E, et al. Bone marrow stromal cell-derived exosomes as communicators in drug resistance in multiple myeloma cells. Blood (2014) 124(4):555-66. doi:10.1182/blood-2014-03-562439

27. Garnier D, Magnus N, Lee TH, Bentley V, Meehan B, Milsom C, et al. Cancer cells induced to express mesenchymal phenotype release exosome-like extracellular vesicles carrying tissue factor. J Biol Chem (2012) 287(52):43565-72. doi:10.1074/jbc.M112.401760

28. Garnier D, Magnus N, Meehan B, Kislinger T, Rak J. Qualitative changes in the proteome of extracellular vesicles accompanying cancer cell transition to mesenchymal state. Exp Cell Res (2013) 319(17):2747-57. doi:10.1016/j.yexcr.2013. 08.003

29. Tauro BJ, Mathias RA, Greening DW, Gopal SK, Ji H, Kapp EA, et al. Oncogenic H-Ras reprograms Madin-Darby canine kidney (MDCK) cell-derived exosomal proteins following epithelial-mesenchymal transition. Mol Cell Proteomics (2013) 2(8):2148-59. doi:10.1074/mcp.M112.027086

30. Jeppesen DK, Nawrocki A, Jensen SG, Thorsen K, Whitehead B, Howard $\mathrm{KA}$, et al. Quantitative proteomics of fractionated membrane and lumen exosome proteins from isogenic metastatic and nonmetastatic bladder cancer cells reveal differential expression of EMT factors. Proteomics (2014) 14(6):699-712. doi:10.1002/pmic.201300452

31. Pasquier J, Thawadi HA, Ghiabi P, Abu-Kaoud N, Maleki M, Guerrouahen BS, et al. Microparticles mediated cross-talk between tumoral and endothelial cells promote the constitution of a pro-metastatic vascular niche through Arf6 up regulation. Cancer Microenviron (2014) 7(1-2):41-59. doi:10.1007/s12307-0130142-2

32. Escola JM, Kleijmeer MJ, Stoorvogel W, Griffith JM, Yoshie O, Geuze HJ. Selective enrichment of tetraspan proteins on the internal vesicles of multivesicular endosomes and on exosomes secreted by human B-lymphocytes. J Biol Chem (1998) 273(32):20121-7. doi:10.1074/jbc.273.32.20121
33. Thery C, Regnault A, Garin J, Wolfers J, Zitvogel L, Ricciardi-Castagnoli P, et al. Molecular characterization of dendritic cell-derived exosomes. Selective accumulation of the heat shock protein hsc73. J Cell Biol (1999) 147(3):599-610. doi:10.1083/jcb.147.3.599

34. Simona F, Laura S, Simona T, Riccardo A. Contribution of proteomics to understanding the role of tumor-derived exosomes in cancer progression: state of the art and new perspectives. Proteomics (2013) 13(10-11):1581-94. doi:10.1002/pmic.201200398

35. Choi DS, Kim DK, Kim YK, Gho YS. Proteomics of extracellular vesicles: exosomes and ectosomes. Mass Spectrom Rev (2014). doi:10.1002/mas.21420

36. Webber JP, Spary LK, Sanders AJ, Chowdhury R, Jiang WG, Steadman R, et al. Differentiation of tumour-promoting stromal myofibroblasts by cancer exosomes. Oncogene (2014). doi:10.1038/onc.2013.560

37. Chairoungdua A, Smith DL, Pochard P, Hull M, Caplan MJ. Exosome release of beta-catenin: a novel mechanism that antagonizes Wnt signaling. J Cell Biol (2010) 190(6):1079-91. doi:10.1083/jcb.201002049

38. Ramteke A, Ting H, Agarwal C, Mateen S, Somasagara R, Hussain A, et al. Exosomes secreted under hypoxia enhance invasiveness and stemness of prostate cancer cells by targeting adherens junction molecules. Mol Carcinog (2013). doi: $10.1002 / \mathrm{mc} .22124$

39. Bijnsdorp IV, Geldof AA, Lavaei M, Piersma SR, van Moorselaar RJ, Jimenez CR. Exosomal ITGA3 interferes with non-cancerous prostate cell functions and is increased in urine exosomes of metastatic prostate cancer patients. J Extracell Vesicles (2013) 2:22097. doi:10.3402/jev.v2i0.22097

40. Felicetti F, Parolini I, Bottero L, Fecchi K, Errico MC, Raggi C, et al. Caveolin-1 tumor-promoting role in human melanoma. Int J Cancer (2009) 125(7):1514-22. doi:10.1002/ijc.24451

41. Hakulinen J, Sankkila L, Sugiyama N, Lehti K, Keski-Oja J. Secretion of active membrane type 1 matrix metalloproteinase (MMP-14) into extracellular space in microvesicular exosomes. J Cell Biochem (2008) 105(5):1211-8. doi:10.1002/jcb.21923

42. Keller S, Konig AK, Marme F, Runz S, Wolterink S, Koensgen D, et al. Systemic presence and tumor-growth promoting effect of ovarian carcinoma released exosomes. Cancer Lett (2009) 278(1):73-81. doi:10.1016/j.canlet.2008.12.028

43. Mathias RA, Chen YS, Wang B, Ji H, Kapp EA, Moritz RL, et al. Extracellular remodelling during oncogenic Ras-induced epithelial-mesenchymal transition facilitates MDCK cell migration. J Proteome Res (2010) 9(2):1007-19. doi:10.1021/pr900907g

44. Atay S, Banskota S, Crow J, Sethi G, Rink L, Godwin AK. Oncogenic KITcontaining exosomes increase gastrointestinal stromal tumor cell invasion. Proc Natl Acad Sci U S A (2014) 111(2):711-6. doi:10.1073/pnas.1310501111

45. Lamouille S, Xu J, Derynck R. Molecular mechanisms of epithelial-mesenchymal transition. Nat Rev Mol Cell Biol (2014) 15(3):178-96. doi:10.1038/nrm3758

46. Gross JC, Chaudhary V, Bartscherer K, Boutros M. Active Wnt proteins are secreted on exosomes. Nat Cell Biol (2012) 14(10):1036-45. doi:10.1038/ ncb2574

47. Beckett K, Monier S, Palmer L, Alexandre C, Green H, Bonneil E, et al. Drosophila S2 cells secrete wingless on exosome-like vesicles but the wingless gradient forms independently of exosomes. Traffic (2013) 14(1):82-96. doi:10.1111/tra.12016

48. Luga V, Zhang L, Viloria-Petit AM, Ogunjimi AA, Inanlou MR, Chiu E, et al Exosomes mediate stromal mobilization of autocrine Wnt-PCP signaling in breast cancer cell migration. Cell (2012) 151(7):1542-56. doi:10.1016/j.cell. 2012.11.024

49. Menck K, Klemm F, Gross JC, Pukrop T, Wenzel D, Binder C. Induction and transport of Wnt 5a during macrophage-induced malignant invasion is mediated by two types of extracellular vesicles. Oncotarget (2013) 4(11):2057-66.

50. Dovrat S, Caspi M, Zilberberg A, Lahav L, Firsow A, Gur H, et al. 14-3-3 and beta-catenin are secreted on extracellular vesicles to activate the oncogenic Wnt pathway. Mol Oncol (2014) 8(5):894-911. doi:10.1016/j.molonc.2014.03.011

51. Lin R, Wang S, Zhao RC. Exosomes from human adipose-derived mesenchymal stem cells promote migration through Wnt signaling pathway in a breast cancer cell model. Mol Cell Biochem (2013) 383(1-2):13-20. doi:10.1007/s11010-0131746-z

52. Ekstrom EJ, Bergenfelz C, von Bulow V, Serifler F, Carlemalm E, Jonsson $\mathrm{G}$, et al. WNT5A induces release of exosomes containing pro-angiogenic and immunosuppressive factors from malignant melanoma cells. Mol Cancer (2014) 13:88. doi:10.1186/1476-4598-13-88 
53. Koch R, Demant M, Aung T, Diering N, Cicholas A, Chapuy B, et al. Populational equilibrium through exosome-mediated Wnt signaling in tumor progression of diffuse large B-cell lymphoma. Blood (2014) 123(14):2189-98. doi:10.1182/blood-2013-08-523886

54. Tadokoro H, Umezu T, Ohyashiki K, Hirano T, Ohyashiki JH. Exosomes derived from hypoxic leukemia cells enhance tube formation in endothelial cells. J Biol Chem (2013) 288(48):34343-51. doi:10.1074/jbc.M113.480822

55. Svensson KJ, Kucharzewska P, Christianson HC, Skold S, Lofstedt T, Johansson $\mathrm{MC}$, et al. Hypoxia triggers a proangiogenic pathway involving cancer cell microvesicles and PAR-2-mediated heparin-binding EGF signaling in endothelial cells. Proc Natl Acad Sci U S A (2011) 108(32):13147-52. doi:10.1073/pnas. 1104261108

56. King HW, Michael MZ, Gleadle JM. Hypoxic enhancement of exosome release by breast cancer cells. BMC Cancer (2012) 12:421. doi:10.1186/1471-2407-12-421

57. Kucharzewska P, Christianson HC, Welch JE, Svensson KJ, Fredlund E, Ringner $\mathrm{M}$, et al. Exosomes reflect the hypoxic status of glioma cells and mediate hypoxiadependent activation of vascular cells during tumor development. Proc Natl Acad Sci U S A (2013) 110(18):7312-7. doi:10.1073/pnas.1220998110

58. Park JE, Tan HS, Datta A, Lai RC, Zhang H, Meng W, et al. Hypoxic tumor cell modulates its microenvironment to enhance angiogenic and metastatic potential by secretion of proteins and exosomes. Mol Cell Proteomics (2010) 9(6):1085-99. doi:10.1074/mcp.M900381-MCP200

59. Zhang J, Ma L. MicroRNA control of epithelial-mesenchymal transition and metastasis. Cancer Metastasis Rev (2012) 31(3-4):653-62. doi:10.1007/s10555012-9368-6

60. Valadi H, Ekstrom K, Bossios A, Sjostrand M, Lee JJ, Lotvall JO. Exosomemediated transfer of mRNAs and microRNAs is a novel mechanism of genetic exchange between cells. Nat Cell Biol (2007) 9(6):654-9. doi:10.1038/ncb1596

61. Gezer U, Ozgur E, Cetinkaya M, Isin M, Dalay N. Long non-coding RNAs with low expression levels in cells are enriched in secreted exosomes. Cell Biol Int (2014) 38(9):1076-9. doi:10.1002/cbin.10301

62. Thakur BK, Zhang H, Becker A, Matei I, Huang Y, Costa-Silva B, et al. Doublestranded DNA in exosomes: a novel biomarker in cancer detection. Cell Res (2014) 24(6):766-9. doi:10.1038/cr.2014.44

63. Yang M, Chen J, Su F, Yu B, Lin L, Liu Y, et al. Microvesicles secreted by macrophages shuttle invasion-potentiating microRNAs into breast cancer cells. Mol Cancer (2011) 10:117. doi:10.1186/1476-4598-10-117
64. Roccaro AM, Sacco A, Maiso P, Azab AK, Tai YT, Reagan M, et al. BM mesenchymal stromal cell-derived exosomes facilitate multiple myeloma progression. J Clin Invest (2013) 123(4):1542-55. doi:10.1172/JCI66517

65. Josson S, Gururajan M, Sung SY, Hu P, Shao C, Zhau HE, et al. Stromal fibroblastderived miR-409 promotes epithelial-to-mesenchymal transition and prostate tumorigenesis. Oncogene (2014). doi:10.1038/onc.2014.212

66. Gu J, Qian H, Shen L, Zhang X, Zhu W, Huang L, et al. Gastric cancer exosomes trigger differentiation of umbilical cord derived mesenchymal stem cells to carcinoma-associated fibroblasts through TGF-beta/Smad pathway. PLoS One (2012) 7(12):e52465. doi:10.1371/journal.pone.0052465

67. Webber J, Steadman R, Mason MD, Tabi Z, Clayton A. Cancer exosomes trigger fibroblast to myofibroblast differentiation. Cancer Res (2010) 70(23):9621-30. doi:10.1158/0008-5472.CAN-10-1722

68. Cho JA, Park H, Lim EH, Lee KW. Exosomes from breast cancer cells can convert adipose tissue-derived mesenchymal stem cells into myofibroblast-like cells. Int J Oncol (2012) 40(1):130-8. doi:10.3892/ijo.2011.1193

69. Abd Elmageed ZY, Yang Y, Thomas R, Ranjan M, Mondal D, Moroz K, et al. Neoplastic reprogramming of patient-derived adipose stem cells by prostate cancer cell-associated exosomes. Stem Cells (2014) 32(4):983-97. doi:10.1002/ stem.1619

Conflict of Interest Statement: The author declares that the research was conducted in the absence of any commercial or financial relationships that could be construed as a potential conflict of interest.

Received: 26 September 2014; accepted: 27 November 2014; published online: 19 December 2014.

Citation: Vella LJ (2014) The emerging role of exosomes in epithelial-mesenchymaltransition in cancer. Front. Oncol. 4:361. doi: 10.3389/fonc.2014.00361

This article was submitted to Molecular and Cellular Oncology, a section of the journal Frontiers in Oncology.

Copyright $\odot 2014$ Vella. This is an open-access article distributed under the terms of the Creative Commons Attribution License (CC BY). The use, distribution or reproduction in other forums is permitted, provided the original author(s) or licensor are credited and that the original publication in this journal is cited, in accordance with accepted academic practice. No use, distribution or reproduction is permitted which does not comply with these terms. 